\title{
The Sweaty Tango
}

\section{Emily Manger}

The apologetic fit

fingers slip

and perspiration drips.

I've got my lips ajar and

as we're sparring

hurry is implicit

every visit's inconsistent

with some different dance to do.

I can only look to you

for the next move to make.

I sweat and yet

you've got exactly what it takes

to make my wallet pour

like a waterfall

and you're so firm and fair

with the authoritarian air you keep

people stare and stay

they watch and wait

you're a modern take

on an age-old institution

a fusion of old and new

movements and transactions

aimed at mutual satisfaction

using clues for what to do

but so elusive in confusion 
poison flash of eyes

from those in line

standing stamping

hands around their shopping

watching as I scramble in this

stilted interaction

fingers tap communication

still inscrutable contraption

leaves me wracked

you beast of fact

your scripted greetings

meet my human clumsiness.

I'm under stress

and it's a mess of guesses

less is more

coins across the floor

the audience will see me crawl

and you as always

calm and sure:

please take your items...

take your items...

take your items...

wait for assistance... 